\title{
A study on relationships between critical success factors of knowledge management and competitive advantage
}

\author{
Afsaneh Zamani Moghaddam ${ }^{\mathrm{a}}$, Morteza Mosakhani ${ }^{\mathrm{b}}$ and Mojgan Aalabeiki ${ }^{\mathrm{c}^{*}}$
}

${ }^{a}$ Assistant Professor, Department of Management and Economy, Science and Research branch, Islamic Azad University, Tehran, Iran

${ }^{b}$ Associate Professor, Department of Management and Economy, Science and Research branch, Islamic Azad University, Tehran, Iran

${ }^{c}$ Master's graduate in EMBA, Department of Management and Economy, Science and Research branch, Islamic Azad University, Tehran, Iran

\section{H R O N I C L E}

Article history:

Received August 16, 2013

Received in revised format

12 September 2013

Accepted 1 November 2013

Available online

November 42013

Keywords:

Knowledge Management

Critical Success Factors of

Knowledge Management

Competitive Advantage

Sustainable Competitive

Advantage

\section{A B S T R A C T}

This paper discusses the relationships between Critical Success Factors (CSF) of knowledge Management (KM) with Competitive Advantage (CA) in automotive industry (Saipa corporate in IRAN). In this research, four categories were used including Human-Oriented factors, Organization, Technology and Management process and their relevant component as independent variables. The research method is based on a descriptive-survey research. The questionnaire includes all CEO and board of director of all firms who worked for Saipa Co, covering 88 companies with 160 managers. To test the hypotheses, SPSS and LISREL software packages were used. For data analysis, descriptive statistics and inferential statistical tests (structural equation modeling, Pearson correlation coefficient) were used. Results taken from structural equation modeling (SEM) proposed measurement model fit and construct validity. Pearson correlation shows there was meaningful relationship between four categories of CSF of $\mathrm{KM}$ and CA when the level of significance was 0.001 .

\section{Introduction}

New business environments are characterized not only by rapid pace of change, but also by discontinuous nature of such changes. Since the 1990s, executives realized that organizations must leverage and exploit intangible assets in the same way, as tangible assets should. This increases their attention towards knowledge management (KM) and expends their efforts (Desouza \& Raider, 2006). Knowledge is now universally accepted as a critical competitive asset, and interest in knowledge management has therefore increased in most business units (Ajmal et al., 2010). Therefore, most organizations need to become aware of necessary factors, which would influence the success of a KM initiative. Ignorance and oversight of the necessary important factors will likely hinder organizational efforts to recognize its full benefit.

* Corresponding author. Tel.: +98-912-8988349

E-mail addresses: Mojalab@yahoo.com (M. Aalabeiki) 
Chuang (2004) developed the concept of KM as an organizational capability and investigated the association between KM capabilities and competitive advantage (CA). The results confirmed the effect of social KM resource on competitive advantage. In addition, technical KM resource was negatively associated with competitive advantage, and KM capability was significantly associated with competitive advantage. Ho (2009) argued that among KM enablers, the factor strategy and leadership was one of the most important KM indices. The relative importance of performance indices in knowledge creation and knowledge internalization on the operational and customer sides indicated a positive, significant relationship in the importance of the financial performance index. Pathirage et al. (2007) highlighted the relative importance of tacit knowledge in construction. They also studied the significant contribution of tacit knowledge towards the organizational performance. Kang (2007) found some correlation among knowledge characteristics and relationships tied on project performance. Many studies suggested organizational culture could substantially promote or hinder the success of KM initiatives (i.e. Tseng, 2010; King, 2008). Marques and Simón (2006) explained how the firms that adopted KM practices achieved better results than their competitors did.

This study aims to fill the identified gaps emerging from a review of prior research in the areas of critical success factors of KM and CA. As such, this research provides a number of practical recommendations for guiding business executives, especially among Iranian firms, to be successful in their KM projects and long-term competitive strategies.

\section{Theoretical background}

\subsection{Knowledge management and critical success factors of it}

There are different understandings of knowledge on the organizational level; a uniform understanding of term knowledge does not exist in KM frameworks. Some of the definitions found in the literature indicate that while some focus on technology-driven KM, most define KM as a set of activities or processes of developing and exploiting knowledge to achieve or enhance a variety of outcomes such as organizational objectives, value, long-term performance, overall success, or CA (Heisig, 2009). A broad range of factors, which influence the success of KM implementation has been mentioned in the literature. For instance, there are some extensive insights about culture, information technology (IT), people, organizational strategy and leadership as important considerations for its accomplishment. However, to the best of authors' knowledge, no systematic work exists on characterizing a collective set of CSFs for implementing KM in the every sector (Wong, 2005). There are several models in this issue, which represent dimensions of KM critical success factors and the proposed model of this paper uses a model presented by Heisig (2009), which is adapted from 160 frameworks around the worldwide. In this model, four categories were constructed for considering context factors, which are critical for the success of KM:

1. Human-oriented factors: culture - people - leadership,

2. Organization: process and structure,

3. Technology: infrastructure and applications,

4. Management process: strategy, goals and measurement.

In the literature, broad consent prevails over the fact that the one-sided emphasis on one of the factors does not correspond to what is generally considered to constitute a holistic KM effort. The task of $\mathrm{KM}$ is to manage these factors as a whole in such a manner that the knowledge-referred activities and/or process can be fulfilled as optimally as possible (Heisig, 2009).

\subsubsection{Culture}

One of the most important and challenging characteristics of KM is to enhance the development of a collaborative, emphatic, trustworthy and helpful organizational culture (Zaim et al., 2007). Culture is the primary criterion of social behavior and integrated action. Organizational cultures represent the 
character of any organization, which directs its employees' day-to-day working relationships and guides them on how to behave and how to communicate within the organization, as well as guiding how the company hierarchy is built (Tseng, 2010).

\subsubsection{Leadership}

It is true in every organization that leaders set the examples for others. Therefore, it is assumed that leaders have direct influence on how the firms should approach and deal with KM processes as well as practices (Singh, 2008). The management thinkers in the area of KM should give importance to leaders and especially to their leadership styles in making things happen for KM processes and practices to flourish.

\subsubsection{People}

People who work for organizations are recognized to be the key enabler for the success of KM implementation. Since knowledge resides in people's heads, human resources are at the heart of creating organizational knowledge. In addition, human interaction is the critical source of intangible value within the intellectual. To stay competitive, organizations require to capitalize on their intellectual assets, especially the intellectual capacity of their workers. Thus, managing people who are willing to generate and share their knowledge is an essential task and finding new sources of motivation to increase people participation in knowledge sharing is a tedious task for most organizations (Nguyen, 2010). Employee development is considered as a way to improve and to enhance the personal value of individuals. The skills and competences of knowledge workers need to be continuously developed in order for them to generate valuable contributions to a particular firm. If not, as with other tangible assets, their value will depreciate. Hence, most firms have to provide appropriate professional development activities for their employees (Wong, 2005).

\subsubsection{Process}

Process is a set of activities, which transform the inputs to outputs in terms of certain order and is an interactive and cross-correlative activity that uses the related resources to transform the inputs into the specific outputs. The process is one of key abilities for the enterprise and it is very important to transmit the customer value and to achieve the objectives of enterprise strategy (Wang \& Xiao, 2009). Knowledge is being continuously created within organizations. Explicit knowledge or information lends itself to systematic handling and widespread dissemination, using techniques of information management. On the other hand, much of the organizational knowledge is tacit and in people's head. Organizations therefore look for different processes and practices, which would help both tacit and explicit knowledge transfer (Celep \& Cetin, 2005).

\subsubsection{Structure}

It has already been pointed out that organizational design is one of the most influential elements as far as the implementation of a KM process is concerned. Given that knowledge plays essential role for the success of all firms and bearing in mind that the way in which they are organized determines the degree in which knowledge circulates both inside the organization and between the organization and its business environment, firms must adopt organizational structures, which helps them create and transfer as much knowledge as possible. It must be remembered that knowledge may sometimes not be taken advantage of as much as it should due to the organization model prevailing in the organization (Claver-cortes et al., 2007).

\subsubsection{Information Technology}

Infrastructure and applications of technology supports KM activities such as knowledge databases, knowledge platforms, performance evaluation systems, and performance integration systems. 
Information technology plays an essential role in supporting the organizational knowledge process. Information technology is tightly associated with KM because it helps distribute structural knowledge vertically and horizontally. (Ho, 2009)

\subsubsection{Strategy and goals}

This provides the foundation for how an organization can deploy its capabilities and resources to reach its KM objectives. In order to increase the significance of KM contribution, it should support an imperative business issue of an organization. It is also essential that employees support this vision and believe that it will work. In addition, clear objectives, purposes and objectives need to be set and understood by everyone involved (Wong, 2005).

\subsubsection{Measurement}

Measurement acts like a data collection system, which gives useful information about a particular situation or activity. An initiative like KM may suffer from the risk of becoming just another management fad, if it is left unmeasured. Measuring KM is necessary to ensure that its envisioned objectives are being attained. Measurement enables organizations to track the progress of KM and to determine its benefits and effectiveness. Essentially, it provides a basis for organizations to evaluate, to compare, to control and to improve the performance of KM (Wong, 2005).

\subsection{Competitive Advantage (CA) and Sustainable Competitive Advantage (SCA)}

Competitive advantage is normally defined as the ability to earn returns on investment consistently above the average for the industry (Porter, 1985). The term, competitive bases, or competitive priorities, has its own roots in manufacturing strategy literature dating the 1960s. According to Ren et al. (2003), there are six basic capabilities including speed, flexibility, cost, quality, innovation and productivity. Sustained competitive advantage is recognized as the level of exceptional performance that a firm attains when it devises and implements a value-enhancing strategy that is not concurrently being followed by any existing or possible competitors and when these firms are either incapable or reluctant to reproduce the benefits of this strategy.

\section{Research model and hypotheses}

According to Heisig (2009), four categories can be constructed for considering context factors, which are critical for the success of KM selected as independent variable (See Fig. 1). This model seems complete because it was selected from 160 framework of critical success factors around the world.

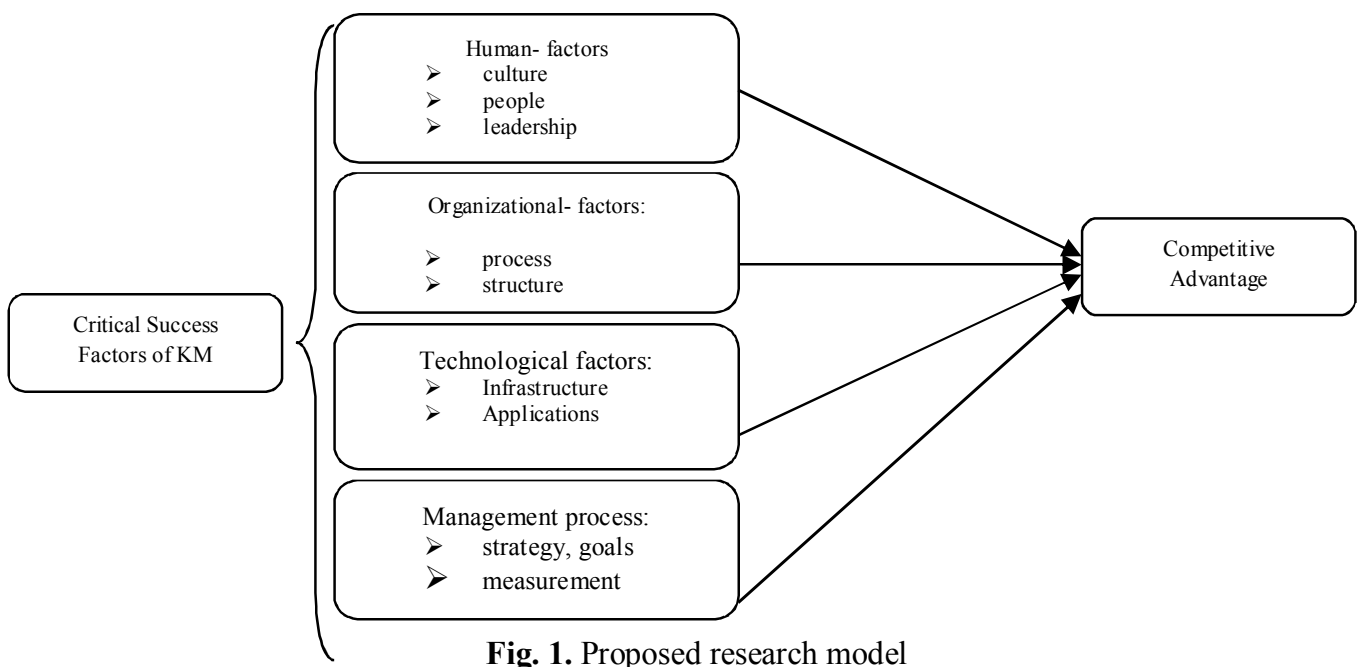

Fig. 1. Proposed research model 
Based on the research model, hypotheses and sub-hypotheses of this research are as follows:

$\mathrm{H}_{1}$ : There is a significant relationship between Human-oriented factors of knowledge management and competitive advantage.

$\checkmark \quad \mathrm{H}_{1-1-}$. There is a significant relationship between organizational culture and competitive advantage.

$\checkmark \quad \mathrm{H}_{1-2}$ - There is a significant relationship between people of firm and competitive advantage.

$\checkmark \quad \mathrm{H}_{1-3-}$ There is a significant relationship between leadership and competitive advantage.

$\mathrm{H}_{2}$ : There is a significant relationship between organizations' factors of knowledge management and competitive advantage.

$\checkmark \quad \mathrm{H}_{2-1}$ : There is a significant relationship between organizational process and competitive advantage.

$\checkmark \quad \mathrm{H}_{2-2}$ : There is a significant relationship between organizational structure and competitive advantage.

$\mathrm{H}_{3}$ : There is a significant relationship between technological factors of knowledge management and competitive advantage.

$\checkmark \quad \mathrm{H}_{3-1}$ : There is a significant relationship between technological infrastructure and competitive advantage.

$\checkmark \quad \mathrm{H}_{3-2}$ : There is a significant relationship between technological application and competitive advantage.

$\mathrm{H}_{4}$ : There is a significant relationship between management process factors of knowledge management and competitive advantage.

$\checkmark \quad \mathrm{H}_{4-1}$ : There is a significant relationship between strategy and goals and competitive advantage.

$\checkmark \quad \mathrm{H}_{4-2}$ : There is a significant relationship between measurement and competitive advantage.

\section{Methodology}

This study is a descriptive and analytic applied research, the survey technique was implemented for collecting the necessary data from the respondents. The questionnaire was designed and developed using the results of the literature review. Some measures were drawn from previous research, while others were created specifically for this study. The draft questionnaire was tested by scholars and experts, which led to minor modifications in the wording of some survey items. These questionnaires were based on a 5-point Likert scale ranging from (1) 'strongly disagree' to (5) 'strongly agree'.

These questionnaires were distributed among all CEOs and board of director of all firms from Saipa corporate, which includes about 88 companies with 160 managers and they played key roles in organizational decisions. Internal consistency measures (Cronbach's $\alpha$ ) were obtained to assess the reliability of the measurement instruments. The reliability of these questionnaires has been measured based on Cronbach alpha and they were 0.983 and 0.925 for critical success factors of knowledge management and competitive advantage, respectively. Descriptive statistics i.e. frequencies, and valid percent were used to describe data. Pearson correlation test was also employed to determine whether or not there were any significant relationships between critical success factors of knowledge management as independent variable and the competitive advantage as dependent variable. The data were analyzed using the statistical package for Social Science (SPSS) and LIZLER.

\section{Results}

The people who participated in our survey are expected to have between 10 to 15 years of job experiences and in our study and the average age was detected as 8.93 years. In terms of educational backgrounds, $49.68 \%$ of the participants hold master's degree, $3.82 \%$ had $\mathrm{PhD}$ degree and $47.13 \%$ finished only a bachelor's degree. Distribution of degrees now represent the largest percentage of respondents in companies with grade one 25.6 percent. We first use some basic statistics such as average, standard deviation, skewness and kurtosis. If the absolute values of skew and kurtosis are between (-1 to 1), the data set are normally distributed (Giles, 2002). Accordingly, values of skew and kurtosis were calculated for the distribution of scores for the CSF of KM and CA in this study 
and they are summarized in Table 1 and Table 2 . All of these values did not exceed the absolute value between ( -1 to 1 ) for skewness and kurtosis indices and moderately normal distribution and the maximum likelihood estimation was used.

Table 1

Skewness and kurtosis statistics for CSF of KM

\begin{tabular}{lcccc}
\hline CSF of KM & Average & Standard Deviation & Skewness & Kurtosis \\
\hline Culture & 3.34 & 1.03 & -0.49 & -0.642 \\
People & 3.14 & 0.89 & -0.27 & -0.678 \\
Leadership & 3.35 & 1.05 & -0.49 & -0.789 \\
Human factors & 3.28 & 0.95 & -0.50 & -0.710 \\
Process & 2.88 & 0.87 & -0.03 & -0.63 \\
Structure & 2.91 & 0.91 & 0.09 & -0.41 \\
Organizational factors & 2.89 & 0.86 & 0 & -0.51 \\
Infrastructure & 3.16 & 0.95 & -0.15 & -0.54 \\
Applications & 3.09 & 0.96 & -0.10 & -0.48 \\
Technological factors & 3.13 & 0.94 & -0.13 & -0.48 \\
Strategy and goals & 3.02 & 0.91 & 0.07 & -0.37 \\
measurement & 2.94 & 0.91 & 0.09 & -0.31 \\
Management process factors & 2.98 & 0.89 & 0.08 & -0.27 \\
\hline
\end{tabular}

Table 2

Skewness and kurtosis statistics for CA

\begin{tabular}{lcccc}
\hline Priorities of CA & Average & Standard Deviation & Skewness & Kurtosis \\
\hline Speed & 2.90 & 0.89 & 0.18 & -0.09 \\
Flexibility & 3.07 & 0.93 & 0.09 & -0.76 \\
Cost & 2.79 & 0.84 & 0.29 & -0.61 \\
Quality & 3.14 & 0.89 & 0.14 & -0.34 \\
Innovation & 3.08 & 0.98 & -0.03 & -0.76 \\
Proactivity & 2.97 & 0.89 & 0.21 & -0.42 \\
\hline
\end{tabular}

Structural Equation Modeling (SEM) has become an extremely popular and powerful multivariate technique in social sciences due to its performance according this criteria and, therefore, SEM was the one analytical tools used to address the fitting of the measurement model in this study. The most important absolute fit indices are the chi-square $(\chi 2)$ statistic, which is sensitive to sample size and model complexity. Chi-Square is likely to be bigger when the sample size or the number of observed variables increases even if the difference between the observed and estimated covariance matrices is identical. The goodness-of-fit index (GFI) is less sensitive to sample size, the root mean square error of approximation (RMSEA) is used to correct the impact of sample size or model complexity on ChiSquare, comparative fit index (CFI) is also an incremental fit index, which is relatively insensitive to model complexity. Table 3 demonstrates the summary of the statistics.

Table 3

Absolute Fit Indices

\begin{tabular}{llllll}
\hline Fit Indices & Chi-Square/df & RMSEA & GFI & AGFI & CFI \\
\hline Results & 2.002 & 0.063 & 0.86 & 0.78 & 0.99 \\
Acceptable Level & $<3$ & $<0.05$ & Poor fit 0 to perfect fit 1 & Poor fit 0 to perfect fit 1 & $>0.9$ \\
Results & Acceptable & Acceptable & Acceptable & Acceptable & Acceptable \\
\hline
\end{tabular}

These fit statistics results suggested that the measurement model provided a reasonably good fit in this study. After the overall structural model fit was assessed and confirmed, the next step was to examine the individual parameter estimates to test the relationships (as presented in Table 4). The results of Pearson correlation showed that the correlation coefficients between all independent variables and dependent variable were positive and significant (all above 0.760), providing strong evidences for the relationships between the aspects of CSFs of knowledge management and CA. Thus, all the research hypotheses are supported by the data. 
Table 4

Summary of Pearson correlation

\begin{tabular}{lccc}
\hline & Person correlation & Significant level & Results of hypotheses \\
\hline Culture & 0.760 & 0.001 & Confirm \\
People & 0.826 & 0.001 & Confirm \\
Leadership & 0.797 & 0.001 & Confirm \\
Human factors & 0.821 & 0.001 & Confirm \\
Process & 0.800 & 0.001 & Confirm \\
Structure & 0.808 & 0.001 & Confirm \\
Organizational factors & 0.829 & 0.001 & Confirm \\
Infrastructure & 0.791 & 0.001 & Confirm \\
Applications & 0.763 & 0.001 & Confirm \\
Technological factors & 0.795 & 0.001 & Confirm \\
Strategy and goals & 0.786 & 0.001 & Confirm \\
Measurement & 0.787 & 0.001 & Confirm \\
Management process factors & 0.802 & 0.001 & Confirm \\
\hline
\end{tabular}

\section{Results and Discussion}

The purpose of this study was to develop a theoretical model of CSFs of KM and CA of the firm and to examine the model in automotive industry in IRAN, empirically. The results of the SEM analyses have indicated that the proposed measurement model and structural model could satisfy the necessary fit conditions. Based on these results, all research hypotheses were tested and confirmed by Pearson correlation.

This study suggests that managers should understand and develop a holistic approach of implementing an overall CSFs of KM, which is composed of four categories including human, organizational, technological and management process factors. The managers should coordinate and synchronize CSFs of KM in terms of four different perspectives to facilitate KM process capability.

They need to keep in mind that more effort should be applied to develop and to utilize these factors. Senior management should clearly support the role of knowledge in corporate success and make sure that their employees understand this issue. Regarding human skills, business managers must emphasize employees' understanding of their own and others' tasks, develop their expertise, and enable them to communicate well with all other organizational members.

There was a significant and positive relationship between organizational aspect and CA. Therefore, the firms of Saipa group should be applied to develop and to utilize organizational factors, especially they should redesign their organizational structure and move towards a flatter and more flexible form that facilitates the sharing and transfer of knowledge across structural boundaries (within and across branches).

There was a significant and positive relationship between technological aspect and CA. therefore, the firms of Saipa group should be applied to developing and utilizing thechnological factors that provide a formal knowledge sharing facility. Organizations also need to take advantage of technological capability to support KM processes. In particular, organizations should use technology to map the location of specific types of knowledge, thereby facilitating the application and sharing of knowledge.

There was a significant and positive relationship between management process aspect and CA. Therefore, the firms of Saipa group should be applied to develop and to utilize management process factors, which improve the power of KM process.

Although this research presents strong evidence regarding the relationship between CSFs of KM and organizational CA, the results should be interpreted in the light of the study's limitations. The study may suffer from potential response bias associated with the single informant and the single technique of data collection used. 
Future research can further investigate CSFs of KM to develop a deeper insight into particular factors of interest, or can explore other factors to provide a more comprehensive picture of the association between organizational $\mathrm{KM}$ and $\mathrm{CA}$. Cross validation studies might also be conducted in different industries in IRAN to improve the the findings.

\section{References}

Ajmal, M., Helo, P., \& Kekale, T. (2010). Critical factors for knowledge management in project business. Journal of Knowledge Management, 14(1), 156-168.

Celep, C., \& Cetin, B. (2005). Teachers' perception about the behaviours of school leaders with regard to knowledge management. International Journal of Educational Management, 19(2), 102 117.

Chuang, S. H. (2004). A resource-based perspective on knowledge management capability and competitive advantage: an empirical investigation. Expert systems with applications, 27(3), 459465.

Claver-Cortes, E., Zaragoza-Saez, P., \& Pertusa-Ortega, E. (2007). Organizational structure features supporting knowledge management processes. Journal of Knowledge Management, 11(4), 45-57.

Desouza, C. K., \& Raider, J. J. (2006). Cutting corners: CKOs and knowledge management. Business Process Management Journal, 12 (2), 129-134.

Giles, D. C. (2002). Advanced research methods in psychology. New York: Rout ledge.

Halawi, L., Aronson, J., \& McCarthy, R. (2005). Resource-Based View of Knowledge Management for Competitive Advantage, The Electronic Journal of Knowledge Management, 3(2), 75-86.

Heisig, P. (2009). Harmonisation of knowledge management - comparing $160 \mathrm{KM}$ frameworks around the global. Journal of Knowledge Management, 13(4), 4-31.

Ho, C.T. (2009), The relationship between knowledge management enablers and performance. Industrial Management \& Data Systems,109(1), 98-117.

Kang, J. (2007). Testing impact of knowledge characteristics and relationship ties on project performance. Journal of Knowledge Management, 11(3), 126-144.

King, W.R. (2008). Questioning the conventional wisdom: culture-knowledge management relationships. Journal of Knowledge Management, 12(3), 35-47.

Marques, D. P., \& Simón, F. J. G. (2006). The effect of knowledge management practices on firm performance. Journal of Knowledge Management, 10(3), 143-156.

Nguyen, T.N.Q. (2010). Knowledge management capability and competitive advantage: an empirical study of Vietnamese enterprises. PhD thesis, Southern Cross University, Lismore, NSW.

Pathirage, C. P., Amaratunga, D.G., \& Haigh, R.P. (2007). Tacit knowledge and organizational performance: construction industry perspective. Journal of Knowledge Management, 11 (1), 115126.

Porter, M. E. (1985). Competitive Advantage. The Free Press, New York, NY.

Ren, J., Yusuf, Y.Y., Burns, N.D. (2003). The effects of agile attributes on competitive priorities: a neural network approach. Integrated Manufacturing Systems, 14(6), 489 - 497.

Singh, S.K. (2008). Role of leadership in knowledge management: a study, Journal of Knowledge Management, 12(4), 3-15.

Tseng, S.M. (2010), The correlation between organizational culture and knowledge conversion on corporate performance. Journal of Knowledge Management, 14 (2), 269-284.

Wang, J., \& Xiao, J. (2009). Knowledge management audit framework and methodology based on processes. Journal of Technology Management in China, 4(3), 239-249.

Wong, K.Y. (2005). Critical success factors for implementing knowledge management in small and medium enterprises, Industrial Management \& Data Systems, 105 (3), 261-279.

Zaim, H., Tatoglu, E., \& Zaim, S. (2007). Performance of knowledge management practices: a causal analysis. Journal of Knowledge Management, 11(6), 54-67. 